\title{
In vivo application of mitochondrial pore inhibitors blocks the induction of apoptosis in axotomized neonatal facial motoneurons
}

\author{
JL Vanderluit $^{1,2,4}$, LT McPhail ${ }^{1,2}$, KJL Fernandes $^{1,2,5}$, \\ NR Kobayashi ${ }^{1,2,5}$ and W Tetzlaff ${ }^{\star}, 1,2,3$ \\ 1 ICORD (International Collaboration on Repair Discoveries), University of \\ British Columbia, Vancouver, British Columbia, Canada V6T $1 Z 4$ \\ 2 Department of Zoology, University of British Columbia, Vancouver, British \\ Columbia, Canada V6T 1 Z4 \\ ${ }^{3}$ Department of Surgery, University of British Columbia, Vancouver, British \\ Columbia, Canada V6T $1 Z 4$ \\ * Corresponding author: W Tetzlaff, Department of Zoology, University of British \\ Columbia, 6270 University Blvd, Vancouver, British Columbia, Canada V6T \\ $1 Z 4$ Tel: +604 822 1675; Fax: +604 822 2416; E-mail: tetzlaff@cord.ubc.ca \\ ${ }^{4}$ Current address: Ottawa Health Research Institute, 451 Smyth Rd, Ottawa, \\ Ontario, Canada \\ ${ }^{5}$ Current address: Hospital for Sick Children, 555 University Ave., Toronto, \\ Ontario, Canada M5G 1X8
}

Received 10.9.02; revised 24.2.03; accepted 10.3.03

Edited by D. Nicholson

\begin{abstract}
Axotomy induces apoptosis in motoneurons of neonatal rodents. To identify the key players in motoneuron apoptosis, we assessed the progression of apoptosis at $4 \mathrm{~h}$ intervals following facial motoneuron axotomy. The mitochondrial release of cytochrome $c$, caspase-3 activation and nuclear condensation were first observed in the motoneuron cell bodies $16 \mathrm{~h}$ postaxotomy. In vivo application of inhibitors of the mitochondrial permeability transition pore, Bongkrekic acid and cyclosporin A prevented cytochrome $c$ release as well as caspase- 3 activation and attenuated motoneuron apoptosis. Similarly, in vivo application of RU360, an inhibitor of the mitochondrial calcium uniporter, also protected axotomized motoneurons from apoptosis. Taken together, our results show that cytochrome $c$ release and subsequent caspase-3 activation are critical events that precipitate the apoptotic death of axotomized neonatal motoneurons in vivo. In addition, these results provide evidence that application of mitochondrial pore inhibitors in vivo can block the induction of apoptosis following motoneuron axotomy.

Cell Death and Differentiation (2003) 10, 969-976. doi:10.1038/ sj.cdd. 4401258
\end{abstract}

Keywords: facial; motoneurons; apoptosis; cell death; caspase3; axotomy

Abbreviations: MPTP, mitochondrial permeability transition pore; ANT, adenine nucleotide translocator; BKA, Bongkrekic acid; CsA, cyclosporin A

\section{Introduction}

Axotomy results in the apoptotic death of motoneurons in neonatal rodents but not of motoneurons in adult rodents, which typically survive axotomy. ${ }^{1-3}$ The induction of apoptosis has been attributed to a loss of trophic factor support as neonatal motoneurons are dependent on target contact for a supply of trophic factors. ${ }^{4-6}$ Loss of trophic support, however, may not be the sole determining factor responsible for neonatal motoneuron apoptosis. Axonal injury results in a massive influx of calcium into the injured axon with concomitant depolarization. ${ }^{7,8}$ Applications of MK-801, an NMDA receptor antagonist, or calcium channel blockers such as flunarizine and cinnarizine rescues motoneurons from axotomy-induced apoptosis suggesting an excitotoxic/ $\mathrm{Ca}^{2+}$ component to motoneuron apoptosis. ${ }^{9-11}$

The activation of apoptosis and the apoptotic pathway responsible for motoneuron death in vivo have yet to be elucidated. Bax, a proapoptotic gene, is required for motoneuron apoptosis as motoneurons in Bax knockout mice survive axotomy. ${ }^{12}$ The proapoptotic actions of Bax are associated with its translocation to the mitochondria followed by the release of death-inducing factors such as cytochrome $c$, caspase-9, AIF and SMAC/Diablo into the cytosol, ultimately resulting in caspase activation. ${ }^{13-19}$ We have previously shown that caspase- 3 is activated following axotomy of neonatal motoneurons and is essential for nuclear condensation. ${ }^{20}$

In vitro studies have shown that, at least in some cases, the release of death-promoting factors from the mitochondria is a crucial step in committing a cell to an apoptotic death. ${ }^{21}$ The mechanism by which proapoptotic factors are released from the mitochondria is presently unclear. Studies have demonstrated the formation of a mega-ion pore, the mitochondrial permeability transition pore (MPTP). ${ }^{22,23}$ Upon opening, the MPTP behaves as a nonselective ion channel allowing a massive influx of $\mathrm{Ca}^{2+}$ and $\mathrm{K}^{+}$into the mitochondrial matrix resulting in loss of mitochondrial membrane potential, swelling due to osmotic changes and eventual rupture of the outer mitochondrial membrane. ${ }^{23}$ Bax has been shown to activate MPTP by interacting with the inner mitochondrial membrane adenine nucleotide translocator (ANT). ${ }^{15,24}$ Excitotoxic insults have also been shown to activate MPTP via an influx of calcium into the mitochondria. ${ }^{25-28}$ Since both excitotoxicity and Bax-mediated apoptotic pathways involve the mitochondria, we hypothesized that MPTP-related changes may play a pivotal role in the induction of apoptosis in axotomized neonatal motoneurons.

\section{Results}

In vitro studies have shown that the release of deathpromoting factors from the mitochondria into the cytosol is a 
crucial step in committing a cell to an apoptotic death. ${ }^{21}$ To determine whether mitochondria release proapoptotic factors following motoneuron axotomy in vivo, sections of the axotomized facial nucleus were examined for the translocation of cytochrome $c$ from mitochondria to cytosol as demonstrated by a change from punctate to diffuse immunostaining. In uninjured PO facial motoneurons, the punctate immunoreactivity of cytochrome $c$ colocalized with the punctate immunostaining of COX IV (Figure 1a,c). At $24 \mathrm{~h}$ following facial motoneuron axotomy in neonatal rats, the immunostaining pattern of cytochrome $c$ became diffuse (Figure 1d) or disappeared completely. In contrast, COX IV immunoreactivity retained its punctate pattern (Figure 1b) consistent with its role as an integral protein of the mitochondrial inner membrane that is not released from the mitochondria during apoptosis.

\section{Mitochondrial release of cytochrome c precedes caspase-3 activation in axotomized motoneurons}

In neonatal rodents, the majority of motoneurons are dead within 3-5 days after axotomy. ${ }^{1}$ Previous studies by Rossiter et al. $^{3}$ and de Bilbao and Dubois-Dauphin, ${ }^{2}$ who each characterized DNA fragmentation and the rate of cell death over 5 days postaxotomy in rats and mice respectively, found that motoneuron cell death within the first $24 \mathrm{~h}$ was $10-20 \%$. In neonatal rats the facial nucleus consists of $\sim 4500$ motoneurons at birth; therefore a loss of $10 \%$ would equal $\sim 450$ motoneurons. Both studies also found that DNA fragmentation appeared to peak at 20 or $28 \mathrm{~h}$ postaxotomy in rats and
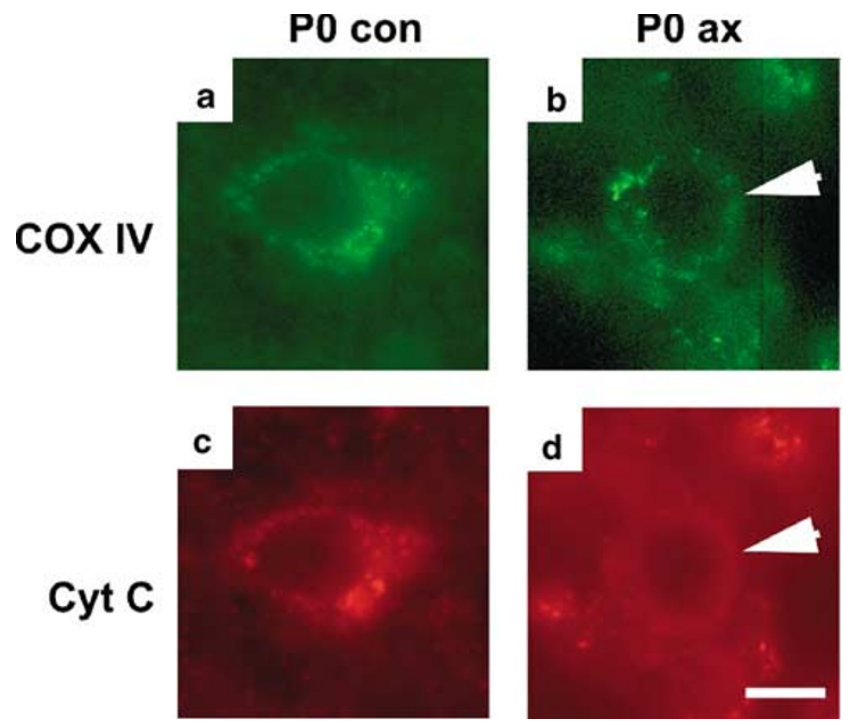

Figure 1 Double immunohistochemistry for cytochrome $c$ and cytochrome oxidase IV (COX IV) of representative motoneurons $24 \mathrm{~h}$ postaxotomy in the axotomized and contralateral nonaxotomized PO facial nuclei. $(\mathbf{a}, \mathbf{c})$ Cytochrome $c$ immunostaining (red) appears punctate and colocalizes with the mitochondrial marker, COX IV (green) in nonaxotomized PO facial motoneurons. (b,d) Following axotomy, cytochrome $c$ immunoreactivity changes from a punctate to a diffuse staining pattern in axotomized P0 motoneurons. The diffuse cytochrome $c$ immunoreactivity no longer colocalizes with COX IV immunoreactivity demonstrating mitochondrial release of cytochrome $c$ into the cytoplasm. Scale bar $=10 \mu \mathrm{m}$ mice, respectively. This was associated with a precipitous loss of $40-50 \%$ of axotomized motoneurons by $48 \mathrm{~h} .{ }^{3,18}$ Therefore, to assess the initiation of apoptosis in axotomized neonatal facial motoneurons, we focused on the first $24 \mathrm{~h}$ postaxotomy.

Motoneuron cell bodies examined at 4,8 and $12 \mathrm{~h}$ postaxotomy were similar to their uninjured counterparts. Cytochrome $c$ immunostaining was punctate, the cell's nucleus was noncondensed and intact, and caspase-3 activation was not observed (Figure 2a,d,g). Following axotomy of PO motoneurons, cytochrome $c$ immunoreactivity changed from a punctate to a diffuse staining pattern, caspase- 3 was activated and nuclei became condensed as shown at $24 \mathrm{~h}$ postaxotomy in Figure $2 \mathrm{~b}, \mathrm{e}, \mathrm{h}$. Increases in the numbers of axotomized PO motoneurons positive for diffuse cytochrome $c$ immunoreactivity, active caspase-3 and condensed apoptotic nuclei were observed at 16 and $24 \mathrm{~h}$ postaxotomy (Figure 3).

In contrast, at $24 \mathrm{~h}$ postaxotomy in adult rats, no motoneurons were found positive for cytochrome $c$ release, active caspase-3 or condensed apoptotic nuclei in either the axotomized or contralateral facial nuclei of the six adult rats examined (Figures 2c,f,i, 3a-d).

In the uninjured contralateral PO facial nucleus, a small number of motoneurons were positive for cytochrome $c$ release and active caspase-3 and had condensed nuclei indicative of developmental cell death as previously reported. $^{20}$

Quantification of cells positive for cytochrome $c$ release, active caspase-3, double-labeling and apoptotic nuclei at $4 \mathrm{~h}$ intervals following PO motoneuron axotomy suggests that these changes take place in the cell soma 16-24 $\mathrm{h}$ postaxotomy (Figure $3 a-d)$. Cytochrome $c$ release, caspase-3 activation and nuclear condensation all occur rapidly within a short time. Examining the staining of motoneurons for diffuse cytochrome $c$, active caspase- 3 and apoptotic nuclei suggested a specific sequence of events.

Active caspase- 3 immunostaining was only observed with either diffuse cytochrome $c$ or a complete loss of cytochrome $c$ immunoreactivity. Since no cell positive for active caspase-3 had punctate (i.e. mitochondrial) cytochrome $c$ immunoreactivity, these results indicate that cytochrome $c$ release may be a prerequisite for caspase-3 activation following motoneuron axotomy.

Similarly, apoptotic, condensed nuclei were only observed in cells immunoreactive for diffuse cytochrome $c$ and active caspase-3 or in cells with a complete loss of cytochrome $c$ and active caspase-3 immunoreactivity, but not in cells with punctate cytochrome $c$. These results suggest that the sequence of events following motoneuron axotomy proceeds with the release of cytochrome $c$ from the mitochondria, followed by caspase- 3 activation and then nuclear condensation.

Numerous cells were observed lacking immunoreactivity for cytochrome $c$ and active caspase-3 but with condensed, apoptotic nuclei. The complete lack of immunoreactivity for cytochrome $c$ and active caspase- 3 in cells with apoptotic nuclei suggests that the duration a cell is immunoreactive for diffuse cytochrome $c$ and active caspase- 3 is shorter than the duration a cell is positive for apoptotic, condensed nuclei. Our 

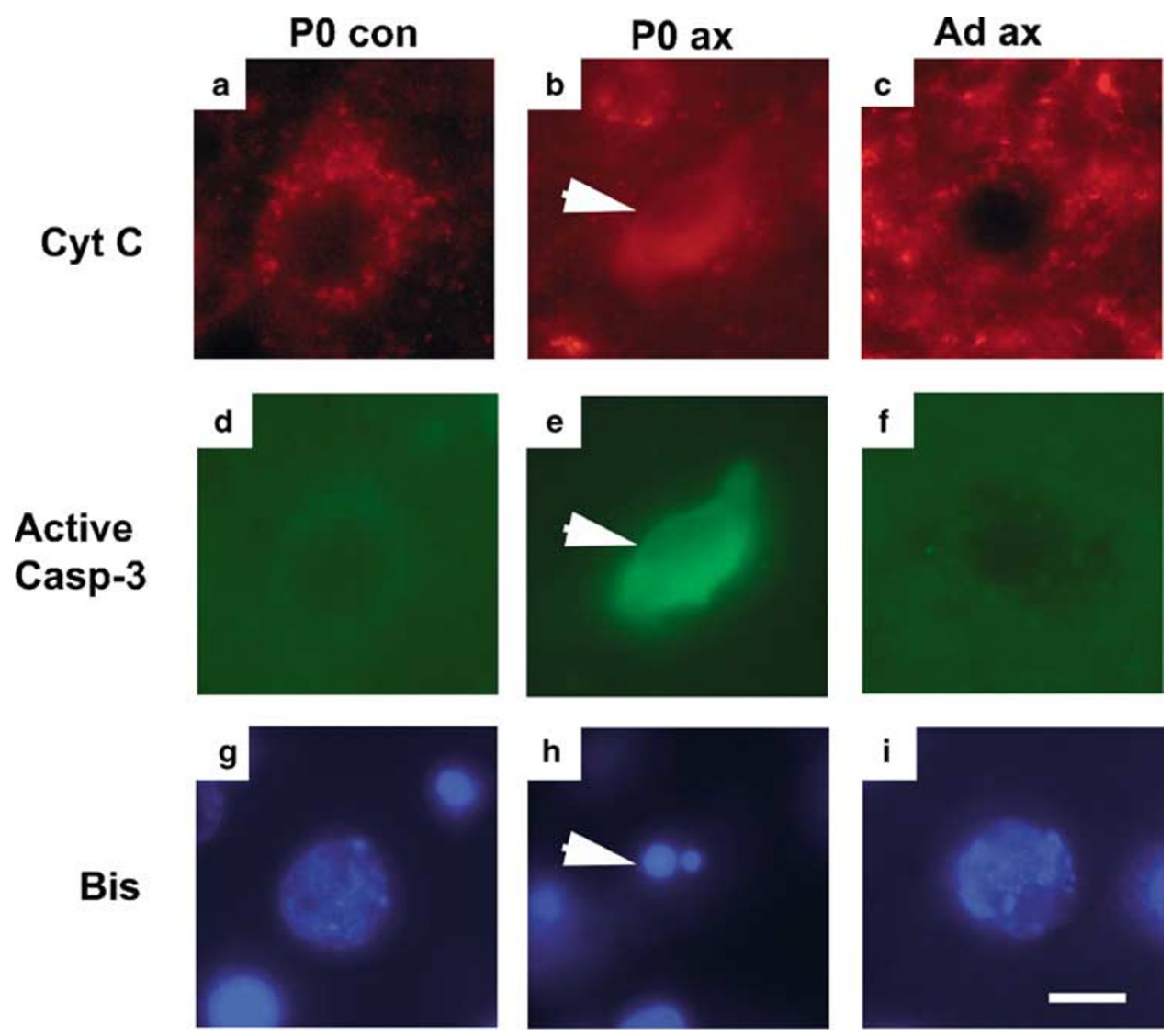

Figure 2 Cytochrome $c$ release and caspase-3 activation occur following neonatal but not adult facial motoneuron axotomy. Representative facial motoneurons immunostained for cytochrome $c$ (red) and active caspase-3 (green) followed by the nuclear stain, bisbenzimide. (a,d,g) Control, uninjured P0 rat facial motoneuron; (b,e,h) a P0 rat facial motoneuron $24 \mathrm{~h}$ following axotomy; (c,f,i) an adult rat facial motoneuron $24 \mathrm{~h}$ following axotomy. Note that $24 \mathrm{~h}$ postaxotomy, cytochrome $c$ immunoreactivity becomes diffuse, caspase- 3 is activated and nuclei are condensed in neonatal motoneurons, whereas axotomized adult motoneurons retain punctate cytochrome $c$ immunoreactivity, do not activate caspase-3 and nuclei remain intact and noncondensed. Scale bar $=10 \mu \mathrm{m}$

quantitative data in Figure 3 demonstrate that the number of apoptotic nuclei was significantly $(P<0.05)$ greater than in uninjured nuclei at $16 \mathrm{~h}$ postaxotomy, whereas the number of cells positive for diffuse cytochrome $c$, or active caspase-3, or both reached significance at $24 \mathrm{~h}$ postaxotomy, when a larger number of cells were undergoing apoptosis. In other words, a longer lasting event results in a larger number of cells that are positive at a given time of observation.

\section{Mitochondrial pore inhibitors block cytochrome c release and axotomy-induced apoptosis}

We have previously shown that caspase-3 is activated during neonatal facial motoneuron apoptosis and is important for the rapid breakdown of the cell and nuclear condensation. Axotomized motoneurons in caspase-3 null mice, however, are not rescued from cell death; rather motoneuron death is delayed. ${ }^{20}$ Since the present data show that diffuse cytochrome $c$ staining occurred prior to caspase-3 activation, we examined whether blocking the release of cytochrome $c$ could prevent activation of caspase-3 and motoneuron apoptosis.

The release of cytochrome $c$ and other proapoptotic proteins from the intermembrane space of mitochondria is believed to occur through a mega-ion pore, the MPTP. The composition of the MPTP is unclear; however, the ANT is believed to be one of the components. ${ }^{23,29}$ In vitro application of inhibitors of the ANT, specifically Bongkrekic acid (BKA) and cyclosporin $A(C s A)$, have previously been shown to block the mitochondrial release of cytochrome $c .^{30-32}$ To determine whether the release of cytochrome $c$ is necessary for activation of apoptosis in vivo, we applied these inhibitors to the axotomized facial nerve. Since few studies have used BKA and CsA in vivo, several different concentrations of each inhibitor were used to determine an effective dosage (data not shown). BKA was found to be toxic at high concentrations $(1 \mathrm{mM})$, had the most significant effect at a dosage of $100 \mu \mathrm{M}$ and was less effective at $10 \mu \mathrm{M}$. CsA was most effective at a concentration of $40 \mathrm{mM}$. Applications of either CsA or BKA on the axotomized nerve stump significantly inhibited the release of cytochrome $c$ in the cell soma in comparison with vehicle control (Figure $4 \mathrm{a}$ ). Blocking the mitochondrial release of cytochrome $c$ also significantly reduced the number of cells positive for active caspase-3 (Figure 4b), double-labeled cells (Figure $4 c$ ) and the number of cells with condensed nuclei (Figure 4d).

Axonal injury results in a massive influx of calcium into the injured axon with concomitant depolarization. ${ }^{7,8,33}$ Previous 

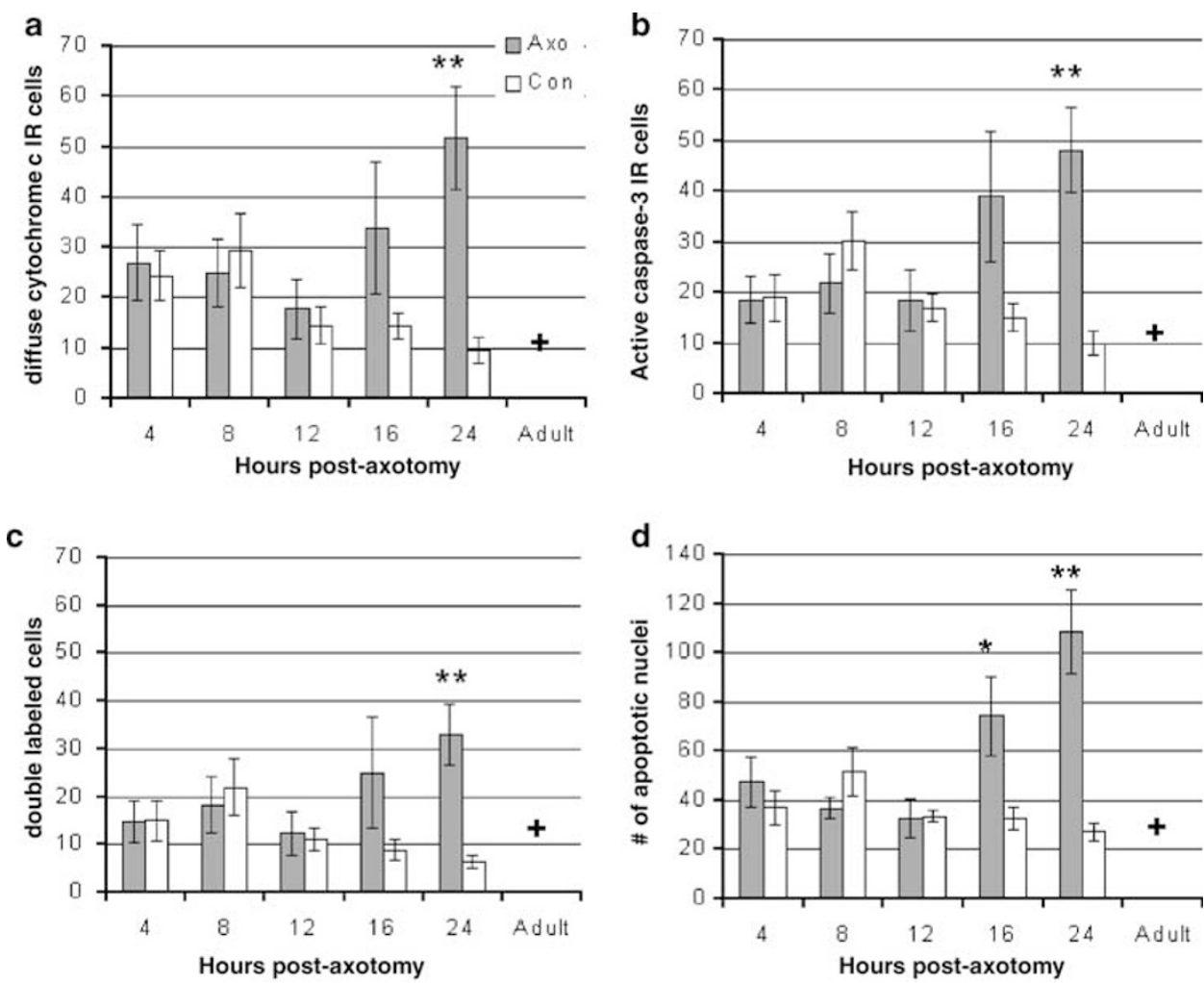

Figure 3 Time course for the release of cytochrome $c$, caspase-3 activation and nuclear condensation following facial motoneuron axotomy. Quantification of the number of motoneurons per facial nucleus that are positive for (a) diffuse cytochrome $c$; (b) active caspase-3; (c) double-labeled (diffuse cytochrome $c$ and active caspase-3 immunoreactivity); and (d) condensed, apoptotic nuclei at 4, 8, 12, 16 and $24 \mathrm{~h}$ following neonatal motoneuron axotomy ( $n=4$ or 5 per time point) and at $24 \mathrm{~h}$ following adult motoneuron axotomy $(n=6)$. ${ }^{*} P<0.05$ and ${ }^{* *} P<0.005$ indicate significance between axotomized and contralateral, nonaxotomized neonatal facial nuclei. $+P<0.001$, significance between axotomized neonatal and axotomized adult facial nuclei at $24 \mathrm{~h}$ postaxotomy
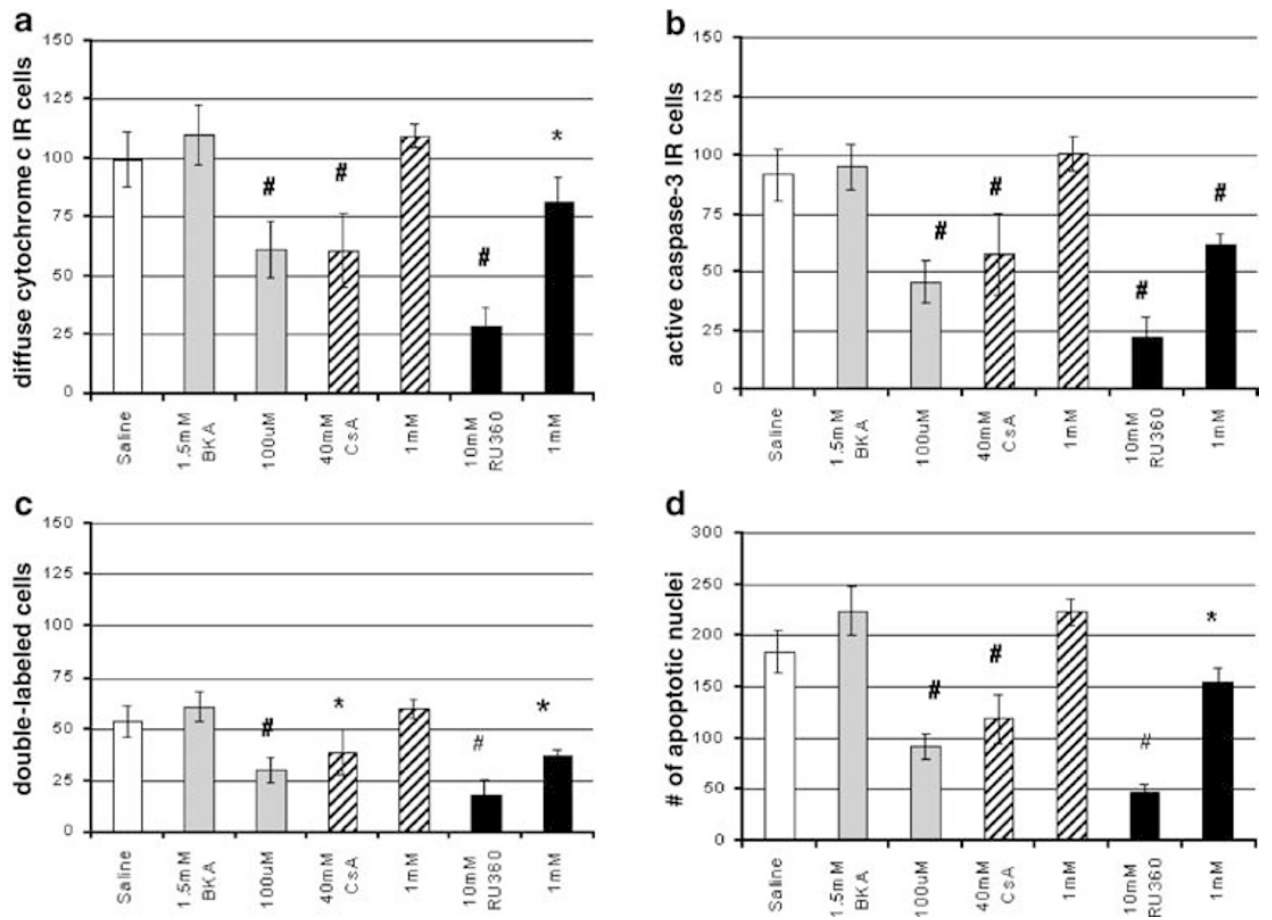

Figure 4 Effect of mitochondrial inhibitors on cytochrome $c$ release, caspase-3 activation and apoptotic nuclei formation $24 \mathrm{~h}$ following facial motoneuron axotomy. Graphs show the number of cells positive for (a) diffuse cytochrome $c$; (b) active caspase-3; (c) double-labeled (diffuse cytochrome $c$ and active caspase-3 immunoreactivity); and (d) condensed apoptotic nuclei per neonatal facial nucleus following treatments of vehicle, CsA, BKA and RU360. ${ }^{*} P<0.05$ and $P<0.01$ indicate significance between vehicle-treated and inhibitor treated 
studies have rescued motoneurons with applications of cation pore inhibitors and the NMDA inhibitor, MK-801, suggesting a role for calcium in motoneuron apoptosis. ${ }^{9-11,34}$ An increase in intramitochondrial calcium has been shown to induce formation of the mitochondrial permeability transition pore. ${ }^{35}$ To further explore whether mitochondrial involvement in motoneuron apoptosis could be attributed to an influx of calcium, we applied RU360, an inhibitor of the mitochondrial calcium channel uniporter, to the injured axons. RU360 significantly inhibited cytochrome $c$ release at both 1 and $10 \mathrm{mM}$ concentrations. It is interesting to note that for each of the pore inhibitors, the dose that significantly blocked the release of cytochrome $c$ also significantly inhibited caspase-3 activation, nuclear condensation and apoptosis (Figure 4a-d).

\section{Discussion}

Using the translocation of cytochrome $c$ from mitochondria to cytosol as a marker of mitochondrial involvement, our results show that cytochrome $c$ release occurs within $24 \mathrm{~h}$ following axotomy of motoneurons in neonatal but not adult rats. Consistent with the sequential relationship of cytochrome $c$ release and caspase-3 activation from in vitro models of apoptosis, caspase- 3 activation occurred rapidly following cytochrome $c$ release and was closely followed by nuclear condensation. Applications of mitochondrial pore inhibitors rescued neonatal motoneurons from axotomy-induced death by blocking the induction of apoptosis.

\section{Time course of apoptosis following motoneuron axotomy}

Immunohistochemical analysis of motoneurons at 4, 8, 12, 16 and $24 \mathrm{~h}$ postaxotomy was performed to study the progression of apoptosis. Axotomy-induced changes in the cell soma were first observed at $16 \mathrm{~h}$ postaxotomy with the mitochondrial release of cytochrome $c$ and caspase-3 activation. These results are consistent with our previous results examining caspase- 3 activation. ${ }^{20}$ Bisbenzimide staining revealed an increase in the number of neurons positive for nuclear condensation by 16 and $24 \mathrm{~h}$ postaxotomy, consistent with the findings of previous studies using terminal deoxynucleotide nick-end labeling (TUNEL) or in situ end-labeling (ISEL) to detect DNA fragmentation. ${ }^{2,3}$ Rossiter et al. ${ }^{3}$ demonstrated that an axotomized motoneuron stains positive for DNA fragmentation (ISEL) for $\sim 2 \mathrm{~h}$. Our results indicate that the number of motoneurons positive for diffuse cytochrome $c$, active caspase-3 or both reached significance at $24 \mathrm{~h}$ postaxotomy. This suggests that the duration a cell is positive for diffuse cytochrome $c$, active caspase-3 or both is shorter than the duration a cell is positive for DNA fragmentation and therefore less than $2 \mathrm{~h}$. Hence, a much greater percent of cells must be undergoing apoptosis before one observes a significant increase in the number of cells immunoreactive for diffuse cytochrome $c$ or active caspase-3 at a given time point.

Motoneuron axotomy in adult rodents does not result in the induction of apoptosis within $24 \mathrm{~h}$, in contrast with motoneurons from neonates (for review see Lowrie and Vrbova ${ }^{1}$ ). Our results support these findings, such that cytochrome $c$ immunoreactivity remained punctate and colocalized to the mitochondria, caspase-3 was not activated and nuclear condensation did not occur.

\section{Cytochrome c release occurs prior to caspase-3 activation in axotomized motoneurons}

Double immunohistochemistry for cytochrome $c$ and active caspase-3 suggested that the release of cytochrome $c$ preceded caspase-3 activation. Motoneurons immunoreactive for active caspase-3 had either diffuse cytochrome $c$ staining or had lost their cytochrome $c$ immunoreactivity all together, while punctate cytochrome $c$ was not observed with activated caspase- 3 in the same cells. In addition, our results using mitochondrial pore inhibitors BKA, CsA, and RU360 not only blocked cytochrome $c$ release but also prevented caspase-3 activation and nuclear apoptosis indicating the caspase-3 activation requires mitochondrial involvement. Collectively, these results demonstrate two distinct points, firstly that mitochondria are involved in axotomy-induced neonatal motoneuron apoptosis and secondly that neonatal motoneuron apoptosis progresses with the mitochondrial release of cytochrome $c$ - followed by caspase- 3 activation - and lastly nuclear condensation.

\section{Mitochondria act at a pivotal point in axotomy-induced motoneuron apoptosis}

Several studies have suggested that the release of proapoptotic factors from the mitochondria during apoptosis occurs through the formation of a mega-ion pore, the MPTP, of which the ANT is believed to be a component. ${ }^{23,29,35}$ In this study, we applied BKA and CsA, pharmacological inhibitors of the ANT, in vivo to determine whether the MPTP was responsible for the release of cytochrome $c$ in motoneuron apoptosis. Application of either BKA or CsA significantly blocked cytochrome $c$ release and subsequent apoptosis. BKA inhibits MPTP by binding to a competitive atractyloside site on the ANT and preventing the transport of ADP into the mitochondria and its subsequent oxidative phosphorylation. ${ }^{36,37} \mathrm{CsA}$ competes for a cyclophilin D binding site on the ANT. ${ }^{23}$ In response to oxidative stress, cyclophilin $D$, a mitochondrial specific cyclophilin, binds to the ANT causing a conformational change in the ANT, thereby making it more sensitive to changes in matrix $\mathrm{Ca}^{2+}$ and activating MPTP. ${ }^{35,38,39}$ The binding of CsA to the closed ANT prevents cyclophilin D from interacting with the ANT and activating MPTP. The ANT is required for the generation of $A T P$, by transporting ADP into the mitochondrial matrix in exchange for ATP; hence, longterm inhibition of the ANT results in a depletion of ATP and in turn ultimately cell death. ${ }^{36,40}$

Short-term in vitro applications of either BKA or CsA have been shown to block mitochondrial-mediated apoptosis, by preventing the loss of mitochondrial membrane potential, cytochrome $c$ release and nuclear condensation. ${ }^{30-32}$ However, Budd et al. ${ }^{41}$ showed that although BKA inhibited mitochondrial membrane depolarization and caspase-3 activation, BKA did not prevent cytochrome $c$ release in 
NMDA-induced cortical neuron death. In addition, in vitro studies suggest that cytochrome $c$ release may in some instances be reversible. ${ }^{42}$ Therefore, it remains a possibility that cells employ different methods of cytochrome $c$ release depending on the cell type and apoptotic stimuli. In this study, cytochrome $c$ release was rapidly followed by caspase-3 activation, and blocking cytochrome $c$ release with mitochondrial pore inhibitors also prevented caspase- 3 activation and apoptosis.

MPTP is also activated by increase in mitochondrial matrix $\left[\mathrm{Ca}^{2+}\right]$ and subsequently results in the release of proapoptotic factors from the mitochondria and caspase- 3 activation. ${ }^{35,43}$ An influx of $\mathrm{Ca}^{2+}$ into the motoneuron soma occurs following motoneuron axotomy through both the lesioned axon and NMDA receptors. ${ }^{9-11,34}$ Application of MK-801, an NMDA receptor antagonist that blocks $\mathrm{Ca}^{2+}$ entry into the cell, rescued $\sim 60 \%$ of axotomized neonatal facial motoneurons ${ }^{9}$ as well as axotomized neonatal sciatic motoneurons ${ }^{10,34,44,45}$ and axotomized adult retinal ganglion cells from apoptosis. ${ }^{46}$ Collectively these results suggest that $\mathrm{Ca}^{2+}$ excitotoxicity plays a role in axotomy-induced apoptosis of neurons.

In the present study, application of RU360 significantly blocked the release of cytochrome $c$, caspase- 3 activation and motoneuron apoptosis. RU360, a ruthenium red derivative, is a polycationic dye that acts as an inhibitor of the mitochondrial calcium uniporter. ${ }^{47,48}$ Long-term application of RU360 is toxic because it disrupts oxidative phosphorylation and causes an increase in intracellular $\mathrm{Ca}^{2+}$ levels. ${ }^{49}$ Our results indicate that short-term application of RU360 in vivo blocks the induction of apoptosis following motoneuron axotomy. Recent in vitro studies have demonstrated that overexpression of Bax in cancer cell lines causes an accumulation of calcium in the endoplasmic reticulum and mitochondria, and subsequently results in the release of proapoptotic factors including cytochrome $c$ from the mitochondria. ${ }^{50,51}$ Application of RU360 effectively blocked the Bax-mediated influx of calcium into the mitochondria, cytochrome $c$ release, caspase activation and apoptosis. ${ }^{50,51}$

Applications of mitochondrial pore inhibitors BKA and CsA also rescue neurons from $\mathrm{Ca}^{2+} /$ excitotoxicity-mediated apoptosis. CsA application prevented the glutamate-mediated increase in mitochondrial $\mathrm{Ca}^{2+}$ and mitochondrial membrane depolarization in neurons in vitro. ${ }^{52}$ Application of CsA in vivo rescued neurons from excitotoxicity-induced death following traumatic brain injury. ${ }^{53-56}$ Similarly, application of BKA in vivo rescued neurons from apoptosis following ischemia by blocking cytochrome $c$ release and the downstream activation of caspases 9 and $3 .^{57}$

Our results support a model whereby the Bax-mediated apoptotic pathway converges with a calcium-mediated apoptotic pathway at the mitochondria to induce MPTP and the release of proapoptotic factors from the mitochondria and subsequent caspase activation. Our results demonstrate that in the presence of Bax expression, the induction of motoneuron apoptosis can be blocked with the application of mitochondrial pore inhibitors. BKA and CsA, inhibitors of the ANT, likely function to directly prevent MPTP activation and the subsequent release of proapoptotic factors from the mitochondria. In contrast, RU360, an inhibitor of the mitochondrial calcium uniporter, appears to function upstream of
MPTP activation by blocking the influx of calcium into the mitochondria. Whether these inhibitors function to directly prevent Bax from interacting with the MPTP/mitochondria or subsequent mitochondrial depolarization requires further inquiry.

In summary, our results show that mitochondria act at a pivotal point in the cell death pathway of axotomized motoneurons. Mitochondrial release of cytochrome $c$ occurs prior to caspase-3 activation and blocking its release from mitochondria also prevents caspase-3 activation and apoptosis demonstrating that mitochondrial involvement is required for the induction of motoneuron apoptosis. In addition, the rescue of axotomized motoneurons with RU360 supports previous findings demonstrating an excitotoxic component in axotomy-induced apoptosis. These results suggest that the excitotoxic cell death pathway converges with the Baxmediated death pathway at the mitochondria.

\section{Methods and Materials}

\section{Animals}

Male and female Sprague-Dawley rats (University of British Columbia's Animal Care Centre, Vancouver, Canada) were maintained in an environment-controlled room with a $12 \mathrm{~h}$ light/dark cycle, and provided with standard rodent chow and water ad libitum. Two litters of rats were used for the developmental study and five litters of rats were used for the mitochondrial inhibitor study. All experiments were approved by the University of British Columbia's Animal Care ethics committee adhering to the Guidelines of the Canadian Council on Animal Care.

\section{Facial motoneuron axotomy}

Axotomy of the left facial nerve was performed on neonatal $(\mathrm{PO})$ rats, hours after birth and on adult male rats at 8 weeks of age. ${ }^{20}$ Neonatal rats were euthanized at $4,8,12,16$ and $24 \mathrm{~h}$ ( $n=5$ per time point) and adults rats $(n=6)$ at $24 \mathrm{~h}$ postaxotomy with a lethal intraperitoneal injection of chloral hydrate $(900 \mathrm{mg} / \mathrm{kg})$ and transcardially perfused with phosphatebuffered saline (PBS, pH 7.4) followed by cold, freshly hydrolyzed $4 \%$ paraformaldehyde in PBS. Brainstems were dissected, cryoprotected in $22 \%$ sucrose in PBS and frozen on dry ice. Frozen brainstems were sectioned at $14 \mu \mathrm{m}$ on a Zeiss cryostat from the rostral to caudal extent of the facial nucleus.

\section{Mitochondrial pore inhibitor application}

Mitochondrial inhibitors were applied by gelfoam (Johnson \& Johnson, Co) to the axotomized facial nerve of neonatal rats. Gelfoam was cut into $5 \mathrm{~mm}^{3}$ pieces and soaked in $10 \mu$ l of one of the following solutions: CsA (1, 10 and $40 \mathrm{mM}$, Novartis Pharma Canada Inc., Canada), BKA (10 $\mu \mathrm{M}$, $100 \mu \mathrm{M}$, and $1 \mathrm{mM}, \mathrm{BIOMOL}$, Plymouth Meeting, PA, USA) and RU360 (1 and $10 \mathrm{mM}$, Calbiochem-Novabiochem Corp., La Jolla, CA, USA) or vehicle (20 mM PBS containing $2 \%$ rat serum albumin and $0.2 \%$ dimethyl sulfoxide) and placed at the site of lesion. The skin was sutured over the gelfoam to keep it in place. The gelfoam remained in the lesion site until the neonates were euthanized at $24 \mathrm{~h}$ postaxotomy. 


\section{Immunohistochemistry}

Double immunohistochemical staining was performed with antibodies to cytochrome oxidase subunit IV (1:500, cat\# A6431, Molecular Probes) and cytochrome $c(1: 1000$, cat\# 665971A, Pharmingen) or cytochrome $c$ and active caspase-3 (1:500, cat\# 559565, Pharmingen, ON, Canada) and incubated overnight at $4^{\circ} \mathrm{C}$. Secondary antibodies, Alexa-conjugated goat anti-mouse $\operatorname{lgG}(1: 200$, Molecular Probes) or Rhodol Greenconjugated goat anti-rabbit IgG $(1: 200$, Molecular Probes, Eugene, OR, USA) and indocarbocyanine (Сy3)-conjugated donkey anti-mouse IgG (Molecular Probes) were applied for $1 \mathrm{~h}$ at room temperature. Sections were stained with bisbenzimide (Hoechst 33258, Sigma Aldrich Chemical Co., Oakville, ON, Canada) and mounted with Sigma ${ }^{\mathrm{TM}}$ mounting medium (Sigma Aldrich Chemical Co.). Immunofluorescent photomicrographs were taken with a SPOT digital colour camera (Diagnostic Instruments Inc., Sterling Heights, MI, USA) mounted on a Zeiss Axioskop compound microscope (Carl Zeiss Inc., Germany).

\section{Cell counts}

A total of 10 sections per neonatal facial nucleus and 12 sections per adult facial nucleus (due to developmental enlargement of nucleus) were collected for counting from the rostral to caudal extent of the nucleus (every fourth section), to avoid counting the same cell twice. Sections from 4-5 different time points and/or treatment groups were mounted on each microscope slide to minimize differences due to treatments of the slides. Sections were immunostained for cytochrome $c$, active caspase-3 and then stained with bisbenzimide (Sigma Aldrich Chemical Co.). An individual, blind to the experimental treatments, counted the number of motoneurons immunoreactive for (i) diffuse cytochrome $c$, (ii) active caspase-3, (iii) double-labeled (diffuse cytochrome $c$ and active caspase3) and (iv) apoptotic nuclei per section of the facial nucleus from neonatal and adult rats ( $n=4-5$ rats/treatment). The criterion for a 'cell positive for cytochrome c release' was assessed as a change in the morphology of the immunostaining pattern from a punctate (cytochrome $c$ within mitochondria) to a diffuse (cytochrome $c$ released into the cytoplasm) staining pattern (see Figures 1d, 2b,e). Cells negative for cytochrome $c$ immunoreactivity were not included in the cytochrome $c$ release counts and probably represent a late stage of the apoptotic process. The criterion for an 'apoptotic nucleus' was complete condensation (i.e. solid circular structures of bisbenzimide staining as shown in Figure $2 \mathrm{~h}$ ).

\section{Statistics}

To determine the total number of cells per facial nucleus that was positive for each (i) diffuse cytochrome $c$, (ii) active caspase-3, (iii) double-labeled (diffuse cytochrome $c$ and active caspase-3) and (iv) apoptotic nuclei, the counts were multiplied by 4 (every fourth section counted) and then multiplied by the Abercrombie correction factor. The Abercrombie correction factor was calculated as follows: $C=T /(T+h)$, where $T=14 \mu \mathrm{m}$ for the section thickness and $h=4 \mu \mathrm{m}$ for the height of the nucleus ( $\sim 3-$ $5 \mu \mathrm{m})$. The mean number of cells per facial nucleus was calculated from $n=4$ or 5 rats/time point or treatment and plotted versus time postaxotomy (Figure 3 ) or plotted versus treatment at $24 \mathrm{~h}$ postaxotomy (Figure 4 ). Student's $t$-tests were performed to compare the mean number of immunopositive cells in the axotomized versus contralateral, uninjured nucleus at each time point, and significant differences were assessed at $\alpha=0.05$. In addition, $t$-tests were used to compare the number of immunopositive cells at $24 \mathrm{~h}$ postaxotomy between adult and neonatal facial nuclei, and significant differences were assessed at values of $\alpha=0.05$. To examine the effect of mitochondria inhibitors, a one-way analysis of variance was performed on the means for each of the treatment groups and a Fisher's LSM post hoc was performed on the individual means, with $P<0.05$ as a significant difference.

\section{Acknowledgements}

We thank Dr. David Park and Dr. Stephen Crocker for critical review of this manuscript and Clarrie Lam and Jody Lecher for excellent technical assistance. This work was supported by grants to WT from the Natural Sciences and Engineering Research Council of Canada and from the British Columbia Neurotrauma Foundation, BCR04. WT is the recipient of the Rick Hansen Man in Motion Foundation Chair in Spinal Cord Research.

\section{References}

1. Lowrie MB and Vrbova G (1992) Dependence of postnatal motoneurones on their targets: review and hypothesis. TINs 15: 80-84

2. de Bilbao F and Dubois-Dauphin M (1996) Time course of axotomy-induced apoptotic cell death in facial motoneurons of neonatal wild type and bcl-2 transgenic mice. Neuroscience 71: 1111-1119

3. Rossiter JP, Riopelle RJ and Bisby MA (1996) Axotomy-induced apoptotic cell death of neonatal rat facial motoneurons: time course analysis and relation to NADPH-diaphorase activity. Exp. Neurol. 138: 33-44

4. Hamburger V (1934) The effects of wing bud extirpation on the development of the central nervous system in chick embryos. J. Exp. Zool. 68: 449-494

5. Oppenheim RW (1989) The neurotrophic theory and naturally occurring motoneuron death. TINS 12: 252-255

6. Oppenheim RW (1991) Cell death during development of the nervous system. Ann. Rev. Neurosci. 14: 453-501

7. Ziv NE and Spira ME (1995) Axotomy induces a transient and localized elevation of the free intracellular calcium concentration to the millimolar range. J. Neurophysiol. 74: 2625-2637

8. George EB, Glass JD and Griffin JW (1995) Axotomy-induced axonal degeneration is mediated by calcium influx through ion-specific channels. J. Neurosci. 15: 6445-6452

9. Casanovas A, Ribera J, Hukkanen M, Riveros-Moreno V and Esquerda JE (1996) Prevention by lamotrigine, MK-801 and $N$ omega-nitro-L-arginine methyl ester of motoneuron cell death after neonatal axotomy. Neuroscience 71: 313-325

10. Lawson SJ and Lowrie MB (1998) The role of apoptosis and excitotoxicity in the death of spinal motoneurons and interneurons after neonatal nerve injury. Neuroscience 87: 337-348

11. Tong JX and Rich KM (1997) Diphenylpiperazines enhance regeneration after facial nerve injury. J. Neurocytol. 26: 339-347

12. Deckwerth TL, Elliott JL, Knudson CM, Johnson Jr EM, Snider WD and Korsmeyer SJ (1996) BAX is required for neuronal death after trophic factor deprivation and during development. Neuron 17: 401-411

13. Gross A, Jockel J, Wei MC and Korsmeyer SJ (1998) Enforced dimerization of $B A X$ results in its translocation, mitochondrial dysfunction and apoptosis. EMBO J. 17: 3878-3885

14. Jurgensmeier JM, Xie Z, Deveraux Q, Ellerby L, Bredesen D and Reed JC (1998) Bax directly induces release of cytochrome $c$ from isolated mitochondria. Proc. Natl. Acad. Sci. USA 95: 4997-5002

15. Narita M, Shimizu S, Ito T, Chittenden T, Lutz RJ, Matsuda $H$ and Tsujimoto $Y$ (1998) Bax interacts with the permeability transition pore to induce permeability transition and cytochrome $c$ release in isolated mitochondria. Proc. Natl. Acad. Sci. USA 95: 14681-14686

16. Du C, Fang M, Li Y, Li L and Wang X (2000) Smac, a mitochondrial protein that promotes cytochrome $c$-dependent caspase activation by eliminating IAP inhibition. Cell 102: 33-42

17. Putcha GV, Deshmukh M and Johnson Jr EM (1999) BAX translocation is a critical event in neuronal apoptosis: regulation by neuroprotectants, BCL-2, and caspases. J. Neurosci. 19: 7476-7485 
18. Deshmukh M and Johnson Jr EM (1998) Evidence of a novel event during neuronal death: development of competence-to-die in response to cytoplasmic cytochrome c. Neuron 21: 695-705

19. Verhagen AM, Ekert PG, Pakusch M, Silke J, Connolly LM, Reid GE, Moritz RL, Simpson RJ and Vaux DL (2000) Identification of DIABLO, a mammalian protein that promotes apoptosis by binding to and antagonizing IAP proteins. Cell 102: 43-53

20. Vanderluit JL, McPhail LT, Fernandes KJL, McBride CB, Huguenot C, Roy S, Robertson GS, Nicholson DW and Tetzlaff W (2000) Caspase-3 is activated following axotomy of neonatal facial motoneurons and caspase- 3 gene deletion delays axotomy-induced cell death in rodents. Eur. J. Neurosci. 12: 3469-3480

21. Kroemer $G$ and Reed JC (2000) Mitochondrial control of cell death. Nat. Med. 6: 513-519

22. Bernardi P, Vassanelli S, Veronese P, Colonna R, Szabo I and Zoratti M (1992) Modulation of the mitochondrial permeability transition pore. Effect of protons and divalent cations. J. Biol. Chem. 267: 2934-2939

23. Bernardi P, Broekemeier KM and Pfeiffer DR (1994) Recent progress on regulation of the mitochondrial permeability transition pore; a cyclosporinsensitive pore in the inner mitochondrial membrane. J. Bioenerg. Biomembr. 26: $509-517$

24. Marzo I, Brenner C, Zamzami N, Jurgensmeier JM, Susin SA, Vieira HL, Prevost MC, Xie Z, Matsuyama S, Reed JC and Kroemer G (1998) Bax and adenine nucleotide translocator cooperate in the mitochondrial control of apoptosis. Science 281: 2027-2031

25. Saikumar P, Dong Z, Patel Y, Hall K, Hopfer U, Weinberg JM and Venkatachalam MA (1998) Role of hypoxia-induced Bax translocation and cytochrome $c$ release in reoxygenation injury. Oncogene 17: 3401-3415

26. Luetjens CM, Bui NT, Sengpiel B, Munstermann G, Poppe M, Krohn AJ, Bauerbach E, Krieglstein J and Prehn JH (2000) Delayed mitochondrial dysfunction in excitotoxic neuron death: cytochrome $c$ release and a secondary increase in superoxide production. J. Neurosci. 20: $5715-5723$

27. Zipfel GJ, Babcock DJ, Lee JM and Choi DW (2000) Neuronal apoptosis after CNS injury: the roles of glutamate and calcium. J. Neurotrauma 17: 857-869

28. Gogvadze V, Robertson JD, Zhivotovsky B and Orrenius S (2001) Cytochrome $c$ release occurs via $\mathrm{Ca}^{2+}$-dependent and $\mathrm{Ca}^{2+}$-independent mechanisms that are regulated by Bax. J. Biol. Chem. 276: 19066-19071

29. Halestrap AP, McStay GP and Clarke SJ (2002) The permeability transition pore complex: another view. Biochimie 84: 153-166

30. Zamzami N, Marchetti P, Castedo M, Hirsch T, Susin SA, Masse B and Kroemer $G$ (1996) Inhibitors of permeability transition interfere with the disruption of the mitochondrial transmembrane potential during apoptosis. FEBS Lett. 384: 53-57

31. Marchetti P, Castedo M, Susin SA, Zamzami N, Hirsch T, Macho A, Haeffner A, Hirsch F, Geuskens M and Kroemer G (1996) Mitochondrial permeability transition is a central coordinating event of apoptosis. J. Exp. Med. 184: $1155-1160$

32. Zamzami N., Brenner C., Marzo I., Susin S.A. and Kroemer, G. (1998) Subcellular and submitochondrial mode of action of Bcl-2-like oncoproteins. Oncogene 16: 2265-2282

33. LoPachin RM and Lehning EJ (1997) Mechanism of calcium entry during axon injury and degeneration. Toxicol. Appl. Pharmacol. 143: 233-244

34. Greensmith L, Mentis GZ and Vrbova G (1994) Blockade of N-methyl-Daspartate receptors by MK-801 (dizocilpine maleate) rescues motoneurones in developing rats. Brain Res. Dev. Brain Res. 81: 162-170

35. Halestrap AP and Davidson AM (1990) Inhibition of Ca2(+)-induced largeamplitude swelling of liver and heart mitochondria by cyclosporin is probably caused by the inhibitor binding to mitochondrial-matrix peptidyl-prolyl cis-trans isomerase and preventing it interacting with the adenine nucleotide translocase. Biochem. J. 268: 153-160

36. Klingenberg M, Grebe K and Heldt HW (1970) On the inhibition of the adenine nucleotide translocation by bongkrekic acid. Biochem. Biophys. Res. Commun. 39: $344-351$

37. Lauquin GJ and Vignais PV (1976) Interaction of (3H) bongkrekic acid with the mitochondrial adenine nucleotide translocator. Biochemistry 15: 2316-2322
38. Connern CP and Halestrap AP (1994) Recruitment of mitochondrial cyclophilin to the mitochondrial inner membrane under conditions of oxidative stress that enhance the opening of a calcium-sensitive non-specific channel. Biochem. J. 302: $321-324$

39. Woodfield K, Ruck A, Brdiczka D and Halestrap AP (1998) Direct demonstration of a specific interaction between cyclophilin- $D$ and the adenine nucleotide translocase confirms their role in the mitochondrial permeability transition. Biochem. J. 336: 287-290

40. Brandolin G, Le Saux A, Trezeguet V, Lauquin GJ and Vignais PV (1993) Chemical, immunological, enzymatic, and genetic approaches to studying the arrangement of the peptide chain of the ADP/ATP carrier in the mitochondrial membrane. J. Bioenerg. Biomembr. 25: 459-472

41. Budd SL, Tenneti L, Lishnak T and Lipton SA (2000) Mitochondrial and extramitochondrial apoptotic signaling pathways in cerebrocortical neurons. Proc. Natl. Acad. Sci. USA 97: 6161-6166

42. Martinou I, Desagher S, Eskes R, Antonsson B, Andre E, Fakan S and Martinou JC (1999) The release of cytochrome $c$ from mitochondria during apoptosis of NGF-deprived sympathetic neurons is a reversible event. J. Cell Biol. 144: 883-889

43. Duchen MR (2000) Mitochondria and calcium: from cell signalling to cell death. J. Physiol. 529 (Part 1): 57-68

44. Mentis GZ, Greensmith L and Vrbova G (1993) Motoneurons destined to die are rescued by blocking $N$-methyl-D-aspartate receptors by MK- 801 Neuroscience 54: 283-285

45. Iwasaki Y, Ikeda K, Shiojima T and Kinoshita M (1995) CNQX prevents spinal motor neuron death following sciatic nerve transection in newborn rats. J. Neurol. Sci. 134: 21-25

46. Kikuchi M, Tenneti $L$ and Lipton SA (2000) Role of p38 mitogen-activated protein kinase in axotomy-induced apoptosis of rat retinal ganglion cells. J. Neurosci. 20: 5037-5044

47. Broekemeier KM, Krebsbach RJ and Pfeiffer DR (1994) Inhibition of the mitochondrial $\mathrm{Ca}^{2+}$ uniporter by pure and impure ruthenium red. Mol. Cell. Biochem. 139: 33-40

48. Tapia R and Velasco I (1997) Ruthenium red as a tool to study calcium channels, neuronal death and the function of neural pathways. Neurochem. Int. 30: $137-147$

49. Velasco I and Tapia R (2000) Alterations of intracellular calcium homeostasis and mitochondrial function are involved in ruthenium red neurotoxicity in primary cortical cultures. J. Neurosci. Res. 60: 543-551

50. Nutt LK, Chandra J, Pataer A, Fang B, Roth JA, Swisher SG, O'Neil RG and McConkey DJ (2002) Bax-mediated $\mathrm{Ca}^{2+}$ mobilization promotes cytochrome $c$ release during apoptosis. J. Biol. Chem. 277: 20301-20308

51. Nutt LK, Pataer A, Pahler J, Fang B, Roth J, McConkey DJ and Swisher SG (2002) Bax and Bak promote apoptosis by modulating endoplasmic reticular and mitochondrial $\mathrm{Ca}^{2+}$ stores. J. Biol. Chem. 277: 9219-9225

52. Schinder AF, Olson EC, Spitzer NC and Montal M (1996) Mitochondrial dysfunction is a primary event in glutamate neurotoxicity. J. Neurosci. 16: $6125-6133$

53. Okonkwo DO and Povlishock JT (1999) An intrathecal bolus of cyclosporin A before injury preserves mitochondrial integrity and attenuates axonal disruption in traumatic brain injury. J. Cerebr. Blood Flow Metab. 19: 443-451

54. Sullivan PG, Thompson MB and Scheff SW (1999) Cyclosporin A attenuates acute mitochondrial dysfunction following traumatic brain injury. Exp. Neurol. 160: 226-234

55. Li PA, Kristian T, He QP and Siesjo BK (2000) Cyclosporin A enhances survival, ameliorates brain damage, and prevents secondary mitochondrial dysfunction after a 30-minute period of transient cerebral ischemia. Exp. Neurol. 165: 153-163

56. Albensi BC, Sullivan PG, Thompson MB, Scheff SW and Mattson MP (2000) Cyclosporin ameliorates traumatic brain-injury-induced alterations of hippocampal synaptic plasticity. Exp. Neurol. 162: 385-389

57. Cao G, Minami M, Pei W, Yan C, Chen D, O'Horo C, Graham SH and Chen J (2001) Intracellular Bax translocation after transient cerebral ischemia: implications for a role of the mitochondrial apoptotic signaling pathway in ischemic neuronal death. J. Cerebr. Blood Flow Metab. 21: 321-333 